ИММУНОГИСТОХИМИЧЕСКИЕ ОСОБЕННОСТИ КОСТНОЙ ТКАНИ СТОПЫ У БОЛЬНЫХ ДИАБЕТИЧЕСКОЙ НЕЙРООСТЕОАРТРОПАТИЕЙ ПРИ САХАРНОМ ДИАБЕТЕ 2 ТИПА

() А.Ю. Токмакова' ${ }^{1}$ Е.А. Коган ${ }^{2}$, Е.Л. Зайцева ${ }^{1 *}$, С.А. Демура², Н.В. Жарков², М.М. Каландия ${ }^{1}$, Г.Р. Галстян ${ }^{1}$

'Национальный медицинский исследовательский центр эндокринологии, Москва

${ }^{2}$ Первый московский государственный медицинский университет имени И.М. Сеченова (Сеченовский университет), Москва

ОБОСНОВАНИЕ. Диабетическая нейроостеоартропатия (ДНОАП, стопа Шарко) - серьезное инвалидизирующее осложнение сахарного диабета как 1, так и 2 типа, которое при отсутствии своевременного адекватного лечения может приводить к формированию длительно не заживающих раневых дефектов стопы и значительно повышать риск высокой ампутации пораженной конечности. В настоящее время причины и механизм развития стопы Шарко до конца неясны. Крайне актуальными являются определение патофизиологических механизмов ее формирования и поиск достоверных маркеров-предикторов данной патологии.

ЦЕЛЬ. Изучить иммуногистохимические особенности костной ткани стопы у пациентов с сахарным диабетом 2 типа (СД2) и ДНОАП по сравнению с лицами с СД2 без этого позднего осложнения.

МАТЕРИАЛЫ И МЕТОДЫ. В Ходе Хирургического вмешательства на стопе выполнен забор фрагмента скелета стопы для выполнения иммуногистохимического исследования маркеров рецепторов к PINP, PIIINP и конечным продуктам гликирования (КПГ) в группе больных с ДНОАП по сравнению с группой контроля.

РЕзУЛЬТАТЫ. В исследование включены 20 пациентов с СД2 и нейропатической формой синдрома диабетической стопы, которые были разделены на 2 группы: 10 пациентов с ДНОАП составили 1-ю группу, 10 пациентов без ДНОАП - 2-ю группу. Пациенты обеих групп были сопоставимы по возрасту, длительности СД2, уровню гликемического контроля. В результате иммуногистохимического исследования было зафиксировано значимое усиление интенсивности окрашивания маркеров рецепторов к N-терминальному пропептиду проколлагена I типа (PINP), N-терминальному пропептиду проколлагена III типа (PIIINP) и КПГ в группе пациентов с ДНОАП по сравнению с группой контроля $(p<0,05)$.

ЗАКЛЮЧЕНИЕ. Впервые проведено иммуногистохимическое исследование маркеров костной резорбции и КПГ у лиц с СД2 и ДНОАП. Полученные результаты свидетельствуют о нарушении коллагенообразования и, как следствие, - формирования и резорбции кости у пациентов с ДНОАП: в 1-й группе выявлено статистически значимое повышение экспрессии PINP, PIIINP и КПГ.

КЛЮЧЕВЫЕ СЛОВА: сахарный диабет 2 типа; нейроостеоартропатия; маркеры; костный метаболизм; морфология; иммуногистохимическое исследование

\title{
IMMUNOHISTOCHEMICAL FEATURES OF THE BONE TISSUE OF THE LOWER EXTREMITIES IN PATIENTS WITH TYPE 2 DIABETES MELLITUS
}

\author{
(c) Alla Yu. Tokmakova', Evgeniya A. Kogan², Ekaterina L. Zaitseva ${ }^{1 *}$, Sofia A. Demura², Nikolay V. Zharkov², \\ Marika M. Kalandiya', Gagik R. Galstyan'
}

'Endocrinology Research Centre, Moscow, Russia

${ }^{2}$ I.M. Sechenov First Moscow State Medical University (Sechenov University), Moscow, Russia

BACKGROUND: Diabetic neuroosteoarthropathy is a serious disabling complication of diabetes mellitus, which, in the absence of timely correct treatment, can lead to high amputations of the affected limb. At present, the reasons and mechanism of the development of Charcot's foot are not completely clear. It is extremely important to determine the pathophysiological mechanisms of DNOAP formation and to search for reliable markers-predictors of this pathology.

AIM: To study the immunohistochemical characteristics of the bone tissue of the lower extremities in patients with diabetic neuroosteoarthropathy in comparison with patients with diabetes mellitus without this pathology.

MATERIALS AND METHODS: During the foot surgery, a bone fragment of the foot was harvested for immunohistochemical study of receptor markers for PINP, PIIINP, and RAGE in the group of patients with DNOAP compared with the control group. 
RESULTS: The study included 20 patients with type 2 diabetes mellitus and were divided into 2 groups: 10 patients with DNOAP made up group 1, 10 patients without DNOAP — group 2.

Patients in both groups were comparable in AGE, experience with type 2 diabetes, and glycemic control.

During the immunohistochemical study, a significant increase in the staining intensity of receptor markers for PINP, PIIINP, and AGE was recorded in the group of patients with DNOAP compared with the control group $(p<0.05)$.

CONCLUSION: For the first time, an immunohistochemical study of markers of bone resorption and AGE was carried out in persons with DNOAP. The results obtained indicate impaired collagen formation and, as a consequence, impaired bone formation and bone resorption in patients with DNOAP: in group 1, a statistically significant increase in the expression of PINP, PIIINP, and RAGE was revealed.

KEYWORDS: type 2 diabetes; diabetic foot; neuroosteoarthropathy; markers; bone metabolism; morphology; immunohistochemistry, AGE

Диабетическая нейроостеоартропатия (стопа Шарко, ДНОАП) - тяжелое осложнение сахарного диабета (СД), которое может привести к развитию грубых деформаций стопы, нарушению ее опороспособности, а также формированию трофических язв. Под ДНОАП понимают прогрессирующее деструктивное неинфекционное поражение костей и суставов на фоне неврологического дефицита.

Распространенность этого осложнения диабета, по данным различных литературных источников, составляет около 0,56\% среди всех пациентов с СД [1]. Качество жизни у этой категории лиц значительно снижается, а риск смертности возрастает [2]. Патогенез ДНОАП полностью не изучен. Считается, что главную роль в ее развитии играют автономная и сенсомоторная полинейропатия, травмы, различные оперативные вмешательства. Остается дискутабельной роль конечных продуктов гликирования (КПГ) в развитии костно-суставных нарушений при СД. Имеются работы, которые демонстрируют существенное негативное влияние КПГ на развитие диабетических осложнений [3].

Оценка морфологических особенностей костной ткани нижних конечностей у пациентов с ДНОАП и без этого осложнения с целью более глубокого изучения его патофизиологических механизмов вызывает большой интерес у специалистов. Известно, что в результате неферментативной реакции между углеводами и свободными аминогруппами белков, нуклеиновых кислот и липидов образуются различные КПГ, которые влияют на свойства коллагена, формирующего костный матрикс [4].

На данный момент известно более 20 типов коллагена, однако к основным относятся I, II, III, V типы. Фибриллы, в состав которых входят коллагены I, II, III типов, составляют основу соединительной ткани организма (хрящи, кости, сухожилия). Коллаген I типа составляет до 90\% органического матрикса и состоит из трех аминокислотных цепей, которые переплетены в виде спирали [5]. Его предшественником является проколлаген I типа, содержащий терминальные фрагменты С и N, при отщеплении которых образуется коллаген. Отделившиеся терминальные фрагменты попадают в межклеточную жидкость, а далее - в периферический кровоток. Диагностически ценным является $\mathrm{N}$-терминальный пропептид проколлагена I типа (PINP), более стабильный в отличие от С-терминального фрагмента. Содержание PINP в костной ткани позволит оценить количество вновь синтезированного коллагена [6].

Избыточное накопление КПГ в волокнах коллагена делает данный белок более жестким и менее восприим- чивым к протеолитическому расщеплению из-за образования неферментативных поперечных сшивок. У пациентов с СД механизм внутриклеточного протеолиза может нарушаться, что приводит к еще большему накоплению свободных продуктов гликирования. Они аккумулируются в зонах развития диабетической микроангиопатии: клубочках почек, периферических нервах, сетчатке глаза [7]. Циркулирующие КПГ соединяются с рецепторами (receptors for advanced glycatedendproducts, или RAGE), которые являются трансмембранными гликопротеинами 1 типа, относящимися к семейству иммуноглобулинов. Под их влиянием в клетках активируется целый ряд сигнальных систем, ответственных за иммунные и воспалительные реакции, пролиферацию и клеточную миграцию [8].

Известно, что гипергликемия подавляет дифференцировку остеобластов и передачу сигналов, что может явиться одной из причин нарушения формирования кости [9]. Еще одно следствие хронической гипергликемии - неферментативное гликозилирование белков (например, коллагена) и других клеточных компонентов (например, ДНК), которые вместе именуются КПГ [10]. Различные КПГ и их рецепторы (RAGE) вовлечены в развитие осложнений диабета, включая поражение скелета стопы у лиц с нарушенным углеводным обменом.

В проведенном исследовании у пациентов с СД 1 типа (СД1) и переломами определялись более высокие уровни КПГ в сыворотке по сравнению с группой сравнения (СД1 без переломов) [11].

Коллаген III типа, фибриллообразующий коллаген, является основным компонентом внеклеточного матрикса во многих внутренних органах и коже. Он также экспрессируется остеобластами зрелой кости. Небольшое количество коллагена III типа также присутствует в коллаген І-содержащих фибриллах костей. Основная роль коллагена III типа в развитии скелета подтверждается его появлением в мезенхимальных конденсатах, предшествующих образованию хряща и кости, востребованностью в нем при ускорении роста остеобластов и его ролью в сохранении остеогенного потенциала мезенхимальных стволовых клеток [12].

Оценка морфологических особенностей костной ткани у пациентов с ДНОАП вызывает интерес в связи с прогрессивным ростом заболеваемости СД и, как следствие, его осложнений. Это позволит глубже изучить патофизиологические механизмы формирования ДНОАП и впоследствии снизить риск развития инвалидизации данной когорты пациентов. 


\section{ЦЕЛЬ ИССЛЕДОВАНИЯ}

Изучить иммуногистохимические особенности костной ткани стопы у пациентов с СД 2 типа (СД2) и ДНОАП по сравнению с больными без данной костной патологии.

\section{МАТЕРИАЛЫ И МЕТОДЫ}

\section{Место и время проведения исследования}

ФГБУ «НМИЦ эндокринологии», отделение диабетической стопы, Первый МГМУ имени И.М. Сеченова Минздрава России (Сеченовский университет), кафедра патологической анатомии. Сбор материала проводился с октября 2019 по декабрь 2020 г.

Изучаемые популяции (одна или несколько)

В исследование включены 20 пациентов с СД2, которые были разделены на 2 группы. 1-ю группу составили больные СД2 с ДНОАП, 2-ю группу составили лица с СД2 без данного осложнения.

\section{Критерии включения:}

1. СД2;

2. возраст до 65 лет;

3. длительность СД2 менее 35 лет;

4. наличие ДНОАП (хроническая стадия).

\section{Критерии невключения:}

1. СД1;

2. наличие гиперпаратиреоза;

3. диабетическая нефропатия, хроническая болезнь почек 4-5-й ст.;

4. наличие острой стадии ДНОАП и остеомиелита (на основании данных анамнеза, клинической картины и результатов рентгенографии и МРТ).

В исследование были включены 20 пациентов. Первую группу составляли лица с СД2 и ДНОАП - 10 человек, 2-я группа (контрольная) была сформирована из пациентов с СД2 и нейропатической формой синдрома диабетической стопы без ДНОАП - 10 человек. Все пациенты были госпитализированы в клинику ФГБУ «НМИЦ эндокринологии» Минздрава России в плановом порядке для проведения хирургического лечения по поводу выраженной деформации стопы, обусловленной хронической стадией ДНОАП, или нейропатической формы синдрома диабетической стопы.

Диагностика хронической стадии нейроостеоартропатии основывалась на оценке состояния периферической иннервации (определение периферической чувствительности и сухожильных рефлексов по стандартной методике), оценке рентгенологической и МРТ-картины (отсутствие очагов остеолиза и отека костного мозга). Раневые дефекты у больных этой группы отсутствовали.

Диагноз нейропатической формы синдрома диабетической стопы у пациентов 2-й группы базировался на клинической картине (наличие длительно незаживающего раневого дефекта плантарной поверхности, Wagner 2-3), результатах оценки артериального кровотока (дуплексное сканирование артерий нижних конечностей) и периферической иннервации, данных рентгенографического исследования (отсутствие остеолиза).
Способ формирования выборки из изучаемой популяции (или нескольких выборок из нескольких изучаемых популяций)

Выборка формировалась путем сплошного включения наблюдений, другая - подбором пар к наблюдениям первой выборки.

\section{Дизайн исследования}

Работа выполнена в дизайне наблюдательного одноцентрового одномоментного контролируемого нерандомизированного исследования.

Для морфологического исследования использовали следующий биопсийный материал:

- фрагменты плюсневых и кубовидных костей от 10 пациентов с хронической стадией стопы Шарко;

- фрагменты плюсневых и кубовидных костей от 10 пациентов с СД без стопы Шарко (контрольная группа).

\section{Описание медицинского вмешательства (для}

интервенционных исследований)

Пациентам в ходе оперативного вмешательства (в 1-й группе - реконструктивные операции по коррекции деформации стопы, во 2-й группе - в ходе хирургической обработки хронического раневого дефекта) производился забор интактного костного фрагмента объемом около $1 \mathrm{~cm}^{3}$. Наличие остеомиелита в образце кости было исключено как клинически (в ходе операции выполнялся забор интактной кости, не имеющей связи с раневым дефектом), так и морфологически в ходе гистологического и иммуногистохимического исследования.

\section{Методы}

Материал фиксировали в 10\% растворе формалина. Морфологический анализ костной ткани включал гистологическое исследование биоптатов костной ткани.

Для светооптического изучения образцы кости фиксировали в 2\% растворе глутарового альдегида на 0,13 М какодилатном буфере и декальцинировали в смеси $\mathrm{Na}_{2}$-ЭДТА и 2\% глутарового альдегида на том же буфере. Материал заключали в парафин. Проводили гистологическую оценку соотношения клеток костной ткани (остеобластов, остеокластов и остеоцитов) и их функционального состояния. Для этого готовили парафиновые срезы толщиной 5 мкм и окрашивали гематоксилином и эозином по стандартной методике. Количественное соотношение клеток считали с помощью окулярной сетки Г.Г. Автандилова. При оценке состояния волокнистых структур учитывали их толщину, направленность и целостность, являющиеся морфологическими критериями их зрелости. Определяли преимущественный тип костной резорбции.

Иммуногистохимическое (ИГХ) исследование проведено на иммуностейнере Leica BOND-MAX (Германия) по стандартному протоколу. В качестве первичных антител для ИГХ-исследования использовались кроличьи поликлональные антитела к специфичному рецептору конечных продуктов гликирования (RAGE) (титр разведения 1:50, Cloud-Clone Corp., США), мышиные моноклональные антитела к РINP-терминальному пропептиду проколлагена I типа (клон С6, титр разведения 1:100, Cloud-Clone Corp., США) и PIIINP-терминальному пропептиду проколлагена III типа (клон Н10, 
титр разведения 1:100, Cloud-Clone Corp., США). При выполнении ИГХ-исследования одновременно с основными реакциями ставились позитивные и негативные контрольные реакции.

Исследование и фотографирование гистологических и ИГХ-микропрепаратов проводилось на микроскопе Olympus BX46 кафедры патологической анатомии (зав. каф. - проф. Коган Е.А.).

Оценка экспрессии маркеров осуществлялась полуколичественным методом с помощью балльной оценки, где 1 «+» - слабо выражено, 2«+» - умеренно выражено, 3 «+» - сильно выражено, 4 «+» - очень сильно выражено.

\section{Статистический анализ}

Полученные в ходе проведения исследования результаты ИГХ-исследований обрабатывались методами описательной статистики (средние значения, стандартные ошибки средних, медианы, моды, стандартные отклонения). Значимость различий средних оценивалась при помощи непараметрического Т-критерия Уилкоксона. Различия считались значимыми при $\mathrm{p}<0,05$.

\section{Этическая экспертиза}

Локальный этический комитет при ФГБУ «НМИЦ эндокринологии» МЗ РФ постановил одобрить возможность проведения данной научно-исследовательской работы, протокол № 2 от 31.01.2018 г. Всеми пациентами подписаны информированные согласия на участие в исследовании.

\section{РЕЗУЛЬТАТЫ}

Исследуемые группы пациентов с СД2 (1-я группа 10 человек, 2-я группа - 10 человек) были сопоставимы по половозрастным характеристикам, длительности диабета и уровню его контроля.

В табл. 1 представлена клинико-лабораторная характеристика обследованных больных.

При лабораторном исследовании у пациентов как 1-й, так и 2-й группы признаков системного воспаления выявлено не было.

\section{Микроскопическое исследование.}

В биоптатах ткани пациентов с ДНОАП имелась костная и костномозговая ткань. В костной ткани - поля

Таблица 1. Клинико-лабораторная характеристика обследованных пациентов (n=20)

\begin{tabular}{|c|c|c|}
\hline Показатель & Группа $1(n=10)$ & Группа $2(n=10)$ \\
\hline Возраст, лет, Ме [25; 75] & $54[49 ; 64]$ & $62[56 ; 69]$ \\
\hline Пол, м/ж & $4 / 6$ & $6 / 4$ \\
\hline Длительность течения СД2, лет Ме [25; 75] & $16[9 ; 25]$ & $13[9 ; 25]$ \\
\hline \multicolumn{3}{|c|}{ Дистальная диабетическая полинейропатия (n): } \\
\hline Нет & 0 & 0 \\
\hline Есть & 10 & 10 \\
\hline \multicolumn{3}{|l|}{ Диабетическая ретинопатия (n) } \\
\hline Отсутствует & 0 & 3 \\
\hline Непролиферативная & 3 & 4 \\
\hline Препролиферативная & 2 & 1 \\
\hline Пролиферативная & 5 & 2 \\
\hline \multicolumn{3}{|l|}{ Диабетическая нефропатия, ХБП, стадия (n) } \\
\hline $\mathrm{C} 1$ & 6 & 6 \\
\hline C2 & 1 & 2 \\
\hline C3a & 1 & 1 \\
\hline C36 & 2 & 1 \\
\hline $\mathrm{HbA}_{1 c^{\prime}} \%, \mathrm{Me}[25 ; 75]$ & $9,0[7,2 ; 10,0]$ & $7.8[6,9 ; 9,8]$ \\
\hline хс-ЛПНП, моль/л, Ме [25; 75] & $3,0[2,4 ; 3,6]$ & $3,2[1,1 ; 6]$ \\
\hline Гемоглобин, г/л, Ме [25; 75] & $120,5[110 ; 126]$ & $137[84 ; 186]$ \\
\hline Лейкоциты, 10/л, Мe [25; 75] & $5,8[5,5 ; 8,7]$ & $7,4[4,7 ; 11,7]$ \\
\hline СОЭ, мм/ч, Me [25; 75] & $33,5[27 ; 39]$ & $22,7[2 ; 88]$ \\
\hline pCKФ (MDRD), мл/мин/1,73 м², Me [25; 75] & $94[71,6 ; 95]$ & $75,0[62,0 ; 86,0]$ \\
\hline Кальций общ., ммоль/л Ме, [25; 75] & $2,2[2,2 ; 2,3]$ & $2,39[2,3 ; 2,45]$ \\
\hline Хронические раны стоп (\%) & 0 & 100 \\
\hline
\end{tabular}

Примечания: группы были сопоставимы по перечисленным характеристикам (р>0,05). СД - сахарный диабет; ХБП - хроническая болезнь почек; хс-ЛПНП - холестерин липопротеинов низкой плотности; рСКФ - расчетная скорость клубочковой фильтрации; СОЭ - скорость оседания эритроцитов. $p$-value $>0,05$ 

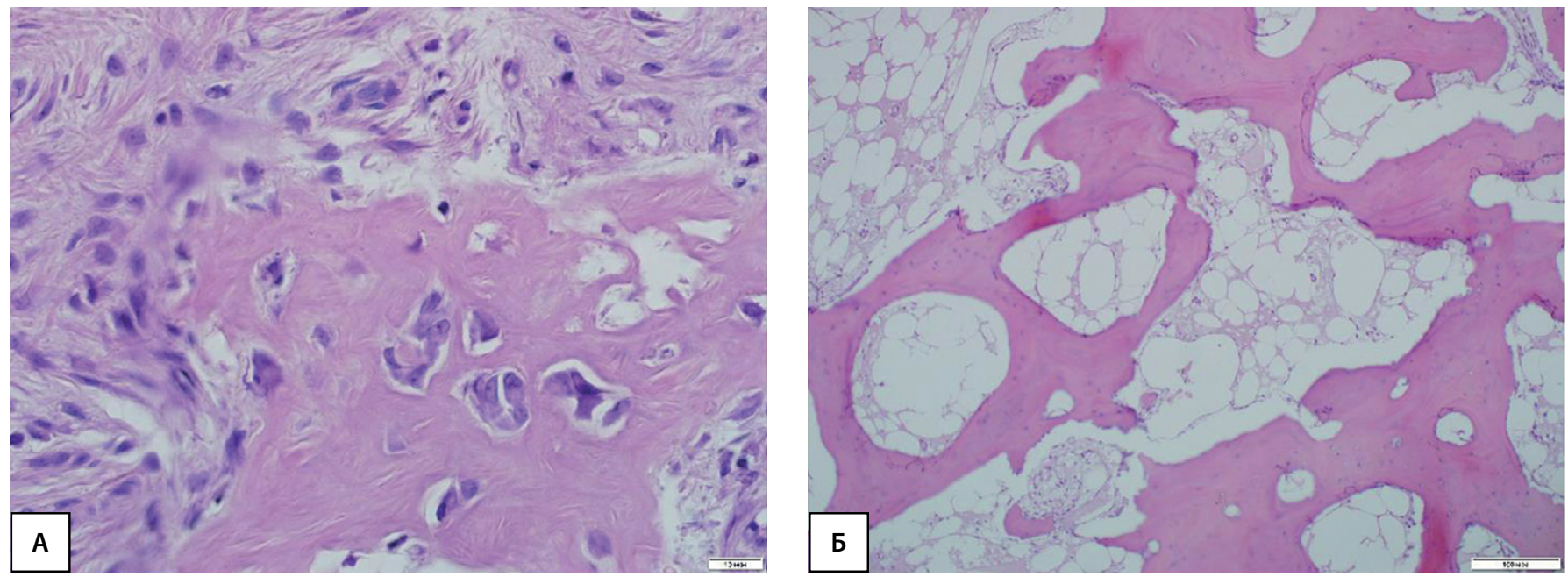

Рисунок 1. Гистологическая картина костной ткани при диабетической нейроостеоартропатии: А 一 поля остеолизиса кости с врастанием в очаги разрушения грануляционной ткани с гиалинозом стенок микрососудов и набуханием эндотелия. Грануляционная ткань содержит выраженные воспалительные инфильтраты и склеротические изменения. В очагах остеолизиса обнаруживается большое количество остеокластов; Б - костная ткань без патологических изменений пациентов с сахарным диабетом (контроль).

остеолизиса кости с врастанием в очаги разрушения грануляционной ткани с гиалинозом стенок микрососудов и набуханием эндотелия. Грануляционная ткань содержала выраженные воспалительные инфильтраты и склеротические изменения. В очагах остеолизиса обнаруживалось большое количество остеокластов (рис. 1А). В биоптатах пациентов контрольной группы также выявлялись фрагменты костной и костномозговой ткани без патологических изменений (рис. 1, Б).

\section{Иммуногистохимическое исследование}

PINP, PIIINP и КПГ обнаруживались в биоптатах ткани пациентов с ДНОАП, цитоплазме фибробластических элементов и клеток воспалительного инфильтрата грануляционной ткани, а также остеокластов в виде коричневой окраски цитоплазмы (рис. 2A, 3А, 4A).

В контрольной группе PINP, PIIINP и КПГ располагались в цитоплазме отдельных остеобластов и клетках костномозговой ткани, имеющих коричневое окрашивание цитоплазмы (рис. 2Б, 3Б, 4Б).

В ходе ИГХ-исследования было зафиксировано значимое увеличение относительного содержания рецепторов к PINP, PIIINP и КПГ в группе пациентов с ДНОАП по сравнению с группой контроля $(p<0,05)$ (рис. 5).

Полученные морфологические и ИГХ-результаты исследования свидетельствуют о патологии коллагенообразования и, как следствие, о нарушении формирования и резорбции кости у пациентов с ДНОАП.

\section{ОБСУЖДЕНИЕ}

Репрезентативность выборок

ДНОАП - достаточно редкое осложнение СД, его распространенность, по данным различных литературных источников, колеблется от 0,16 до 18\% среди всех пациентов с СД.

В исследование были включены пациенты, проходившие лечение в специализированном отделении диабетической стопы ФГБУ «НМИЦ эндокринологии».
Выборка репрезентативна, а полученные данные могут быть экстраполированы на общую популяцию.

Сопоставление с другими публикациями

Сопоставление с данными литературы затруднительно ввиду их отсутствия.

Полученные результаты исследования ИГХ-особенностей костного метаболизма у пациентов с СД2 и ДНОАП выполнены впервые.

Интересно, что в группе с ДНОАП определялась более активная экспрессия коллагенов I и III типов, в отличие от группы контроля.

На рис. 1-4 представлена ИГХ-картина биоптатов костных фрагментов у лиц с ДНОАП и группы контроля.

Таким образом, можно предположить, что активная перманентная травматизация и усиленный кровоток вызывают нарушение выработки и формирования коллагенов и интенсификации костного ремоделирования, что приводит к формированию ДНОАП.

Кроме того, в исследовании зафиксировано избыточное накопление КПГ в группе со стопой Шарко. Это может провоцировать дисбаланс формирования и резорбции кости у лиц с СД2 и служить прогностическим маркером формирования ДНОАП.

В исследовании D. Farlay и соавт. было отмечено, что пациенты с СД1 и повышенными значениями КПГ сыворотки крови имели более высокие риски переломов, чем пациенты с нормальными значениями КПГ крови [11].

Ввиду отсутствия морфологических исследований оценки накопления КПГ в костной ткани сопоставить полученные результаты с данными литературы не представляется возможным.

\section{Клиническая значимость результатов}

Полученные данные о повышении экспрессии PINP и PIIINP подтверждают предположение, что нарушение синтеза коллагена при СД2 может служить причиной формирования ДНОАП. 

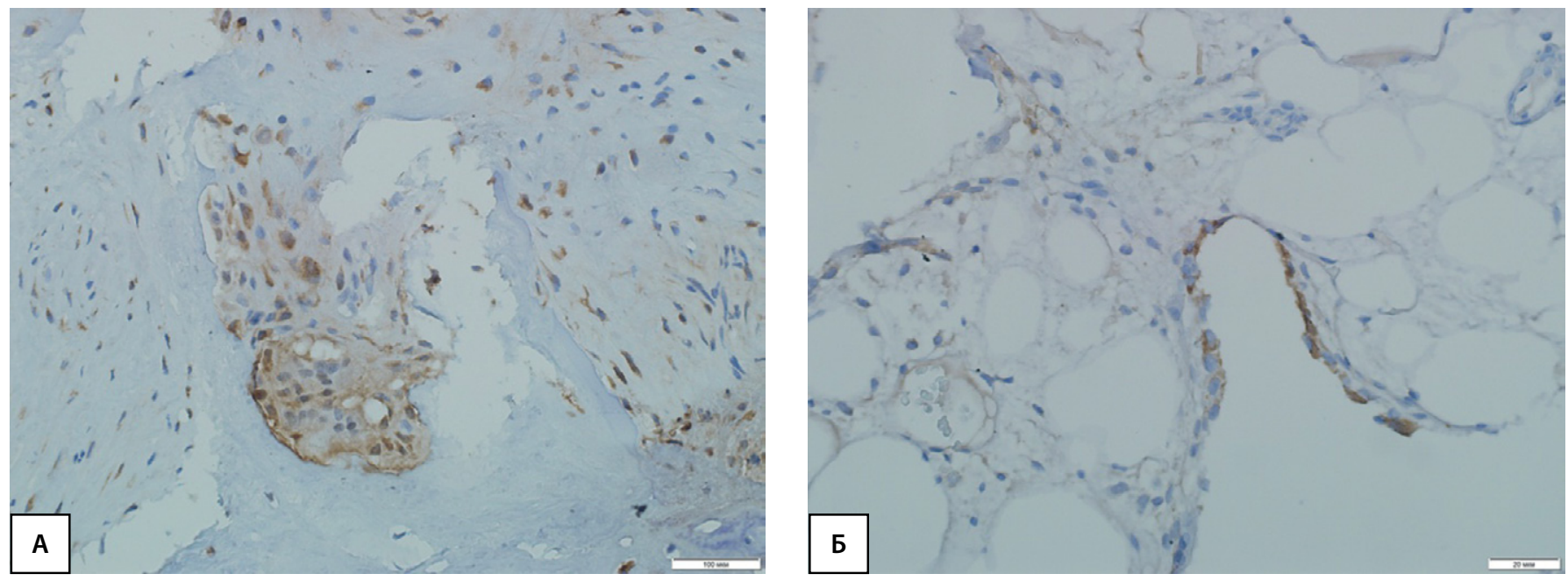

Рисунок 2. Иммуногистохимическая картина экспрессии PINP в костной ткани: А — высокая экспрессия маркера в фибробластических элементах и клетках воспалительного инфильтрата грануляционной ткани, а также в остеокластах у пациентов с диабетической нейроостеоартропатией; Бслабая экспрессия маркера в отдельных остеобластах и клетках костного мозга у пациентов контрольной группы.
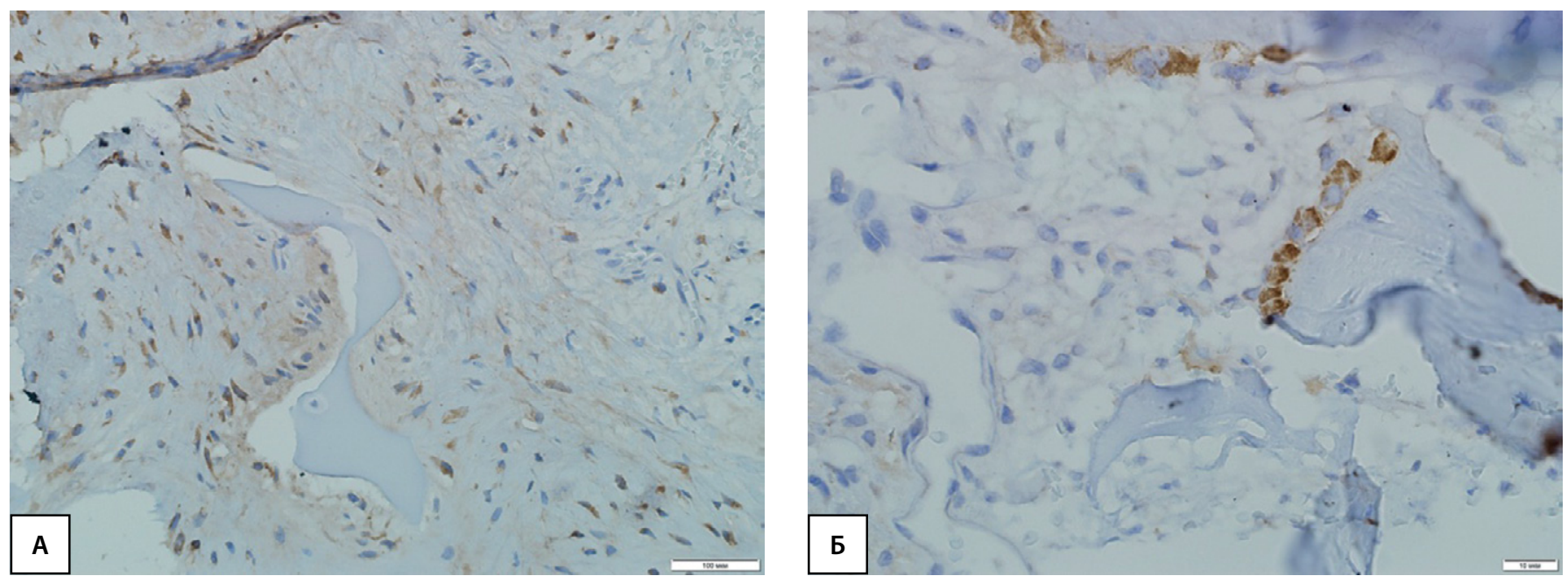

Рисунок 3. Иммуногистохимическая картина экспрессии РІІІNP в костной ткани: А - высокая экспрессия маркера в фибробластических элементах и клетках воспалительного инфильтрата грануляционной ткани, а также в остеокластах у пациентов с диабетической нейроостеоартропатией; Б слабая экспрессия маркера в отдельных остеобластах и клетках костного мозга у пациентов контрольной группы.
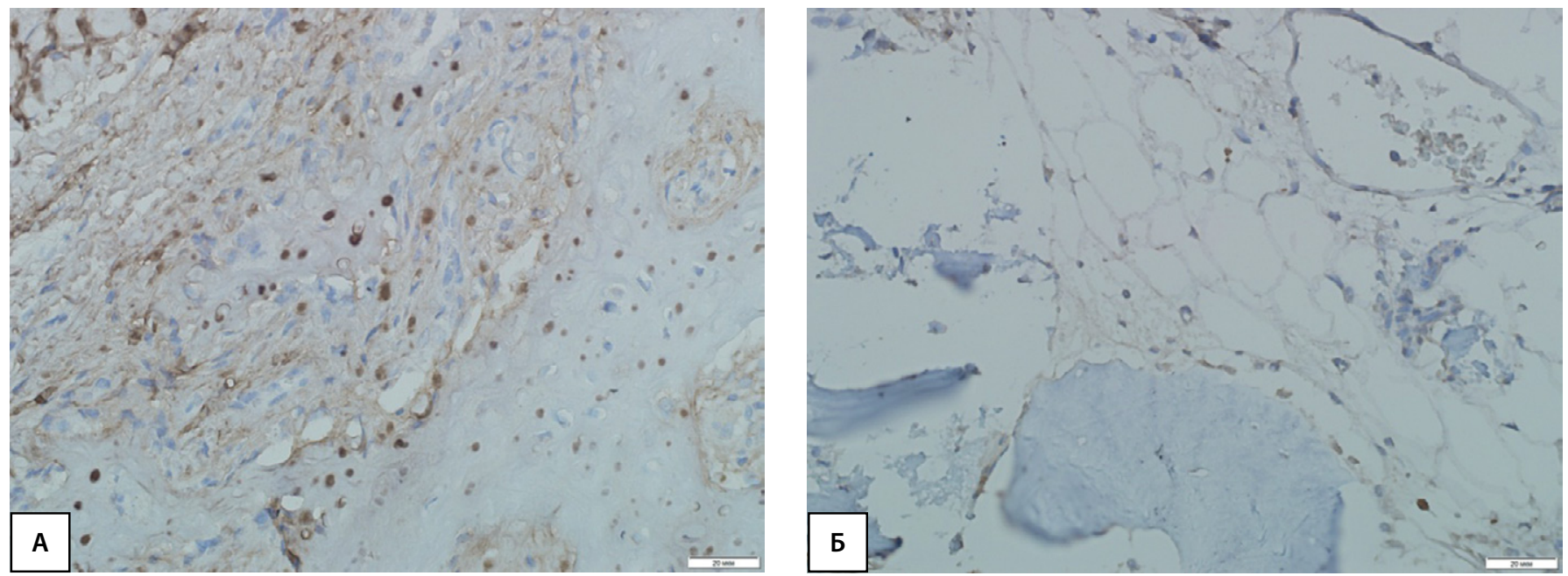

Рисунок 4. Иммуногистохимическая картина экспрессии рецепторов КПГ в костной ткани. А-умеренная экспрессия маркера в фибробластических элементах и клетках воспалительного инфильтрата грануляционной ткани, а также в остеокластах у пациентов с диабетической нейроостеоартропатией; Б - слабая экспрессия маркера в отдельных остеобластах и клетках костного мозга у пациентов контрольной группы. 
$100 \%$

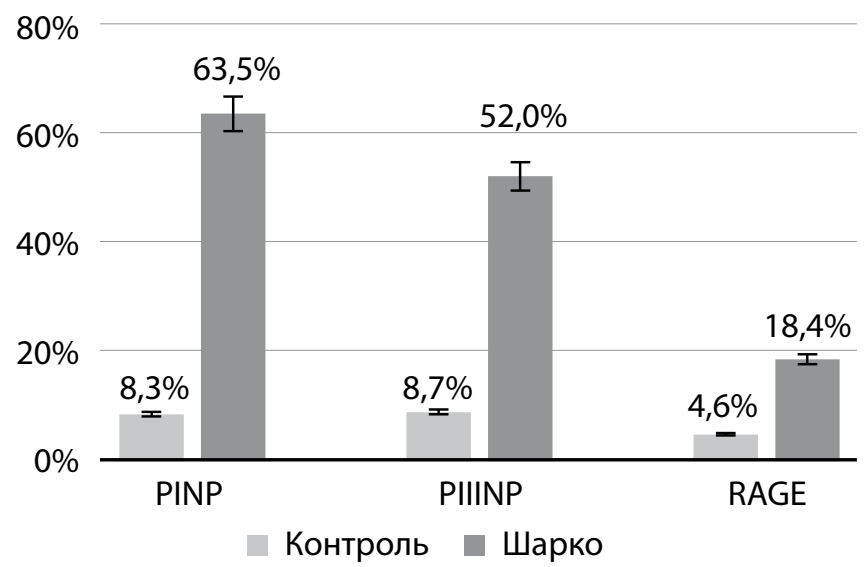

Рисунок 5. Иммуногистохимическая характеристика PINP, PIIINP и КПГ в биоптатах костной ткани при диабетической нейроостеоартропатии (стопа Шарко) и без нее (контроль).

Кроме того, можно предположить, что повышенная экспрессия рецепторов КПГ у лиц с ДНОАП может быть следствием генетической детерминированности и являться прогностическим маркером формирования ДНОАП у лиц с СД2.

\section{Ограничения исследования}

Данное исследование было пилотным. Относительно невысокая распространенность ДНОАП ограничивает включение большого количества пациентов и формирование большей выборки. Требуется проведение дальнейших исследований на большей выборке.

Для определения прогностической значимости выявленных маркеров ДНОАП следует провести корреляцию с уровнями данных маркеров в сыворотке крови.

\section{Направления дальнейших исследований}

Следующим этапом исследования будет являться определение и изучение корреляций уровней PINP, PIIINP и КПГ в сыворотке крови и данных ИГХ-исследования.

\section{ЗАКЛЮЧЕНИЕ}

Впервые проведено ИГХ-исследование маркеров костной резорбции и КПГ у лиц с ДНОАП. Полученные результаты свидетельствуют о нарушении коллагенообразования и, как следствие, о нарушении формирования и резорбции кости у пациентов с СД2 и ДНОАП: в группе 1 выявлено статистически значимое повышение экспрессии рецепторов PINP, PIIINP и КПГ.

\section{ДОПОЛНИТЕЛЬНАЯ ИНФОРМАЦИЯ}

Источники финансирования. Исследование выполнено в рамках НИР «Иммунологические, биохимические и гуморальные факторы и их роль в терапевтическом прогнозе при сахарном диабете 2 типа».

Конфликт интересов. Авторы декларируют отсутствие явных и потенциальных конфликтов интересов, связанных с содержанием настоящей статьи.

Участие авторов. Токмакова А.Ю. - разработка дизайна исследования, написание статьи; Коган Е.А. - разработка дизайна исследования, проведение морфологического и ИГХ-исследования, микрофотографирование препаратов, написание статьи; Демура С.А. - проведение морфологического и ИГХ-исследования, написание статьи; Жарков Н.В. - проведение ИГХ-реакций, статистика, написание статьи; Зайцева Е.Л. - сбор клинического материала, его анализ, написание статьи; Каландия М.М. - сбор клинического материала, его анализ, написание статьи; Галстян Г.Р. - разработка дизайна исследования, написание статьи. Все авторы одобрили финальную версию статьи перед публикацией, выразили согласие нести ответственность за все аспекты работы, подразумевающую надлежащее изучение и решение вопросов, связанных с точностью или добросовестностью любой части работы.

Благодарности. Авторы выражают благодарность сотрудникам отделения диабетической стопы ФГБУ «НМИЦ эндокринологии» Минздрава России, врачам-лаборантам и сотрудникам кафедры патологической анатомии ПМГМУ им. Сеченова (Сеченовский университет) за помощь в подготовке и получении результатов для данной публикации.

\section{СПИСОК ЛИТЕРАТУРЫ | REFERENCES}

1. Svendsen OL, Rabe OC, Winther-Jensen M, Allin KH. How Common Is the Rare Charcot Foot in Patients With Diabetes? Diabetes Care. 2021;44(4):e62-e63. doi: https://doi.org/10.2337/dc20-2590

2. Strotman PK, Reif TJ, Pinzur MS. Charcot Arthropathy of the Foot and Ankle. Foot \& Ankle International. SAGE Publications; 2016;37(11):1255-1263. doi: https://doi.org/10.1177/1071100716674434

3. Mascarenhas JV, Jude EB. The Charcot Foot as a Complication of Diabetic Neuropathy. Curr Diab Rep. 2014;14(12):1-9. doi: https://doi.org/10.1007/s11892-014-0561-6

4. Wautier JL, Schmidt AM. Protein glycation: A firm link to endothelial cell dysfunction. CircRes. 2004;95(3):233-238 doi: https://doi.org/10.1161/01.RES.0000137876.28454.64

5. Saito M, Soshi S, Fujii K. Effect of hyper- and microgravity on collagen post-translational controls of MC3T3-E1 osteoblasts. J Bone Miner Res. 2003;18(9):1695-1705. doi: https://doi.org/10.1359/jbmr.2003.18.9.1695

6. Seibel MJ. Biochemical markers of bone turnover: part I: biochemistry and variability. Seibel MJ Clin Biochem Rev. 2005;26(4):97-122.
7. Kanazawa I. Interaction between bone and glucose metabolism. Endocr J. 2017;64(11):1043-1053. doi: https://doi.org/10.1507/endocrj.EJ17-0323

8. Lee EJ, Park JH. Receptor for Advanced Glycation Endproducts (RAGE), Its Ligands, and Soluble RAGE: Potential Biomarkers for Diagnosis and Therapeutic Targets for Human Renal Diseases. Genomics Inform 2013;11(4):224. doi: https://doi.org/10.5808/gi.2013.11.4.224

9. McCabe LR. Understanding the pathology and mechanisms of type I diabetic bone loss. J Cellular Biochem. 2007;102:1343-1357. doi: https://doi.org/10.1002/jcb.21573

10. Sanguineti R, Puddu A, Mach F, et al. Advanced glycation end products play adverse proinflammatory activities in osteoporosis. Mediators Inflamm. 2014;2014:975872 doi: https://doi.org/10.1155/2014/975872

11. Farlay D, Armas LA, Gineyts E, et al. Nonenzymatic glycation and degree of mineralization are higher in bone from fractured patients with type 1 diabetes mellitus. J Bone Mineral Res. 2016;31(1):190-195. doi: https://doi.org/10.1002/jbmr.2607

12. Volk SW, Shah SR, Cohen AJ, et al. Type III collagen regulates osteoblastogenesis and the quantity of trabecular bone. Calcif Tissue Int. 2014;94(6):621-631. doi: https://doi.org/10.1007/s00223-014-9843-x 


\section{ИНФОРМАЦИЯ ОБ АВТОРАХ [AUTHORS INFO]}

*Зайцева Екатерина Леонидовна, к.м.н. [Ekaterina L. Zaitseva, MD, PhD]; адрес: Россия, 117036, Москва, ул. Дм. Ульянова, д. 11 [address: 11 Dm.Ulyanova street, 117036 Moscow, Russian Federation]; ORCID: https://orcid.org/0000-0002-3735-019X; eLibrary SPIN: 1075-3022; e-mail: zai.kate@gmail.com

Токмакова Алла Юрьевна, д.М.н. [Alla Yu. Tokmakova, MD, PhD]; ORCID: https://orcid.org/0000-0003-2474-9924; eLibrary SPIN: 7479-7043; e-mail: alla-tokmakova@yandex.ru

Коган Евгения Алтаровна, профессор, д.м.H. [Evgeniya A. Kogan, MD, PhD, Professor];

ORCID: https://orcid.org/0000-0002-1107-3753; eLibrary SPIN: 2709-2449; e-mail: koganevg@gmail.com

Демура Софья Александровна, к.м.н. [Sofia A. Demura, MD, PhD]; ORCID: https://orcid.org/0000-0001-9717-5496; eLibrary SPIN: 9220-4883; e-mail: sarah3618@gmail.com

Каландия Мария Малхазовна, клинический аспирант [Mariya M. Kalandiya, PhD student]; e-mail: marika525@mail.ru Жарков Николай Владимирович, старший лаборант [Nikolay V. Zharkov, senior laboratory assistant];

ORCID: https://orcid.org/0000-0001-7183-0456; eLibrary SPIN: 8812-9731; e-mail: zharkov_n_v@staff.sechenov.ru

Галстян Гагик Радикович, Д.М.Н., профессор [Gagik R. Galstyan, MD, PhD, Professor];

ORCID: https://orcid.org/0000-0001-6581-4521; eLibrary SPIN: 9815-7509; e-mail: galstyangagik964@gmail.com

\section{ЦИТИРОВАТЬ:}

Токмакова А.Ю., Коган Е.А., Зайцева Е.Л., Демура С.А., Жарков Н.В., Каландия М.М., Галстян Г.Р. Иммуногистохимические особенности костной ткани стопы у больных диабетической нейроостеоартропатией при сахарном диабете 2 типа // Сахарный диабет. - 2021. — T. 24. — №5. — C. 448-455. doi: https://doi.org/10.14341/DM12812

\section{TO CITE THIS ARTICLE:}

Zaitseva EL, Tokmakova AYu, Kogan EA, Demura SA, Kalandiya MM, Galstyan GR. Immunohistochemical features of the bone tissue of the lower extremities in patients with diabetes mellitus. Diabetes Mellitus. 2021;24(5):448-455. doi: https://doi.org/10.14341/DM12812 